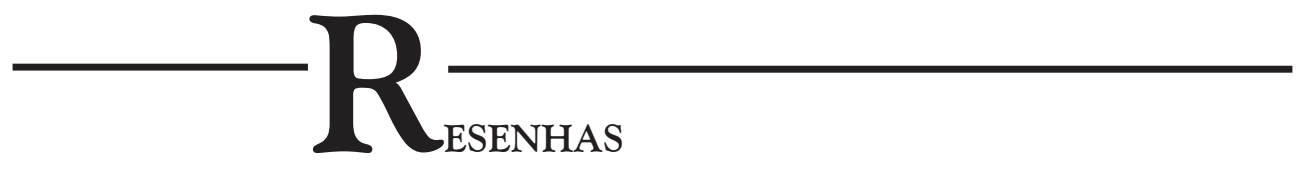

TEIXEIRA, Faustino; MENEZES, Renata (Orgs.). Religiões em movimento: o censo de 2010. Petrópolis, Vozes, 2013, 360pp.

\title{
O CENSO DE 2010: RELIGIÕES EM MOVIMENTO, PERSPECTIVAS EM DIÁlOGO
}

\author{
Rodrigo Toniol \\ Universidade Federal do Rio Grande do Sul - Porto Alegre \\ Rio Grande do Sul - Brasil
}

A crítica antropológica parece já ter nos acostumado a acompanhar, pelo menos a cada dez anos, uma tendência de filiação da produção sobre religião às análises macrossociológicas. Em que pese as contínuas oscilações epistemológicas da disciplina, esse movimento, que mobiliza especialistas de todo o país a refletir sobre a situação da religião no Brasil e da religião dos brasileiros, está associado com a divulgação dos resultados de um dispositivo de governo, os números do censo. Década por década temos acumulado reflexões sobre nosso "retrato religioso" e feito dele uma espécie de horizonte de convergência para o desdobramento de diálogos e debates absolutamente diversos ${ }^{1}$. Essa disposição em tratar dos números do censo, contudo, antes de chamar a atenção pela regularidade, importa pelo crescimento do interesse dos cientistas 
sociais. $\mathrm{O}$ censo, nesse caso, passa a constituir-se não somente como uma série de longa duração privilegiada para identificar as transformações na filiação religiosa no Brasil, como também num tópico disciplinar que permite colocar a própria produção especializada em perspectiva.

Religiões em movimento: o censo de 2010, organizado por Faustino Teixeira e Renata Menezes, cumpre esse duplo empreendimento, repercutindo as estatísticas sobre religião no país a partir de análises apuradas e ainda colocando o próprio instrumento de contagem e seus usos no centro da reflexão. Os 19 capítulos do livro e seu prefácio, escritos por 24 autores, estão distribuídos em dois eixos temáticos. Primeiro, um grupo de textos dedicados a refletir sobre os números relativos às denominações e grupos religiosos específicos, sendo o tema e seus autores os seguintes ${ }^{2}$ : catolicismo, Carlos Rodrigues Brandão e Sílvia Regina Alves Fernandes; evangélicos de missão, Leonildo Silveira Campos; igrejas pentecostais, Cecília L. Mariz e Paulo Gracino Jr;; sem religião, Regina Novaes; espiritismo, Bernardo Lewgoy; religiões afro-brasileiras, Reginaldo Prandi, Luciana Duccini e Miriam Rabelo; tradições indígenas, Elizabeth Pissolato; religiões orientais, Frank Usarski; islamismo, Paulo Gabriel Hilu da Rocha Pinto; judaísmo, Monica Grin e Michel Gherman; Nova Era, Leila Amaral. O segundo eixo concentra as considerações sobre as tendências mais gerais sugeridas pelo censo de 2010, tais como as apontadas nos capítulos de Faustino Teixeira, Antônio Flávio Pierucci e Marcelo Camurça, e também as reflexões sobre o papel do censo para as ciências sociais da religião, cujos textos exemplares são os de Clara Mafra, Renata Menezes e o prefácio de Pierre Sanchis. Sob pena de tornar os argumentos de cada um dos capítulos difusos, não cabe aqui retomá-los. Por isso, na tentativa de produzir uma compreensão mais ampla da obra, opto por tentar fazê-los dialogar a partir da recorrência de alguns temas-chave.

Ao refletir sobre o sincretismo no campo religioso brasileiro, Pierre Sanchis, em um texto do início dos anos $2001^{3}$, afirmou a existência de uma referência generalizada e constante ao cristianismo - e mais especificamente ao catolicismo. Nas próprias palavras de Sanchis, ${ }^{4}$ "vale perguntarmo-nos se estas mutações [do campo religioso] não continuariam acompanhando os lineamentos de uma antiga lógica”. O que está em jogo nesse tipo de afirmação é o reconhecimento de certa insistência de uma matriz cultural católica na sociogênese da nação, de modo que mesmo as transformações no quadro geral das identidades religiosas não significariam uma ruptura absoluta com a cultura católico-brasileira. Esse tipo de associação entre identidade nacional e catolicismo, o qual tem em Sanchis uma de suas muitas formulações, contribuiu para que as análises sobre o censo religioso, pelo menos desde a década de 1950, sejam feitas no âmbito de uma "sociologia do catolicismo em declínio", como afirmou Pierucci ${ }^{5}$. "Mesmo os estudos sociológicos sobre as religiões não católicas, ao enfocarem a expansão quantitativa ou qualitativa de outra confissão que não a católica, estarão sempre

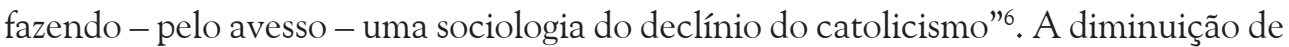
católicos, contudo, como Pierucci insiste, é simplesmente a mudança nos conteúdos 
de uma cultura que permanece cristã e que mesmo assim "avança a primeira década do novo século, nada nada, com 123 milhões de católicos declarados em 190 milhões de habitantes. É católico que não acaba mais"7. O debate sobre o tema, que anima cientistas sociais da religião desde as publicações de Cândido Procópio Ferreira de Camargo ${ }^{8}$ sobre os censos de 1940, 1950 e 1960, reverbera noutro par de relação presente nas discussões de Religiões em movimento: pluralismo e pluralidade.

Diante da emergência da categoria de "evangélico não determinado", Sanchis, em seu prefácio, afirma ser esta a expressão de uma nova modalidade e intensidade do histórico pertencimento fluido, compósito e eventualmente múltiplo dos brasileiros. A novidade, afirma o antropólogo, estaria no avanço da reconhecida pluralidade religiosa, desta para um pluralismo. Isso é uma pluralidade reconhecida, legítima, benéfica, que, convertida em valor, deve doravante orientar o comportamento relacional dos fiéis (:14). A importância do campo evangélico para essa nova modulação do pluralismo religioso também é destacada por Marcelo Camurça que, em diálogo com a socióloga Sílvia Fernandes, assevera: "pluralismo sim, mas, sobretudo, com o avanço evangélico" (:71). Nesse caso, se o pluralismo no Brasil permanece binário", no censo de 2010 ele ganha feições evangélicas. Cabe, então, a pergunta: se o valor de legitimidade e reconhecimento associado com a pluralidade religiosa segue sendo cristã, quais seriam seus efeitos para as religiões afro-brasileiras? Números (outra vez) subestimados, afirma Reginaldo Prandi. Esse é um diálogo latente no capítulo de Prandi, que esperava que o novo clima de liberdade religiosa que se respira cada vez mais entre nós, e um provável aumento no nível de conscientização, resultante de movimentos de dessincretização das religiões afro-brasileiras, contribuíssem no sentido de resolver a questão de identidade mal-definida - ou mesmo negada por parte dos afro-religiosos (:205).

Os números sobre religião que, como disse Renata Menezes, atingiram repercussões notáveis, ocupando espaços importantes na mídia nacional e nas revistas especializadas, não podem ser considerados apenas por sua suposta objetividade. Sublinhar os modos pelos quais os dados de um instrumento como o censo funcionam, fazendo de indivíduos uma população, ajuda a dimensionar a densidade do campo de interesse por essas estatísticas (:243). É justamente por conta do reconhecimento dessa capacidade - aqui, especificamente relativa aos números sobre religião - que o IBGE, segundo Clara Mafra, teria postergado em quase dois anos a divulgação dos resultados, numa atitude de ocultamento e precarização das informações. "A divulgação tardia dos dados censitários sobre religião não foi resultado de um simples problema técnico, mas decorre de uma decisão política institucional” (:39). Para Clara Mafra, a precariedade das perguntas e os problemas na sistematização dos dados despertariam uma sensação generalizada de desconfiança nos resultados, o que faria com que especialistas e religiosos os rejeitassem. Carlos Rodrigues Brandão também aponta para a insuficiência da pergunta sobre o conteúdo da confissão religiosa feita pelos recenseadores - Qual é a sua religião? - e indica a necessidade de realização de uma outra pergunta, dessa vez, sobre a forma da vivência religiosa - Como você vive a sua religião? -, o que permitiria 
a realização de análises que pretendem extrapolar a autodeclaração do pertencimento e explorar aspectos da prática religiosa.

Ainda sobre os resultados divulgados pelo IBGE, os autores que tematizaram os dados de religiões específicas se uniram em um coro uníssono para indicar a subrepresentação expressa pelos números. Os pentecostais, os sem-religião, os espíritas, os indígenas, os adeptos das religiões orientais, os afro-religiosos, os new agers, os muçulmanos, os judeus foram, para seus analistas, subdimensionados. Sobre os afroreligiosos, por exemplo, Reginaldo Prandi chega a dizer que no Brasil correspondem a, pelo menos, o dobro da população sugerida pelo censo. A recorrência dessas notas sobre as diferenças entre os números do censo e os obtidos por meio de outras pesquisas não deixa de chamar a atenção. Afinal, não é o censo um instrumento da ciência estatística que, antes de simplesmente identificar os religiosos do país, os produz como adeptos? Bernardo Lewgoy é preciso ao dizer que as perguntas sobre raça e religião utilizadas nos censos não apenas refletem como também ajudam a produzir a realidade neles contida. Renata Menezes encaminha-se nessa direção quando assinala o efeito de reificação desse dispositivo: se as identidades são construídas e contextuais, o Censo as apresenta como reais. Se elas são fluidas, locais e circunstanciais, o Censo as apresenta como gerais e substantivas (:340). Assim, sobrescrever os números do censo com estimativas mais reais não teria como efeito perverso aumentar ainda mais seu caráter reificante?

A divulgação dos dados do censo religioso também parece ser um momento privilegiado para a elaboração de agendas de pesquisa para a década seguinte. Tratamse de investigações que se projetam não em função dos números, mas muitas vezes apesar deles. É pelo reconhecimento de que é preciso matizar alguns dados, desdobrálos, questioná-los ou mesmo estendê-los que alguns pesquisadores se mobilizam para novos empreendimentos analíticos. Religiões em movimento concentra, de modo raro, alguns dos desenhos dessa agenda de interesse.

Diante da ascendente indústria cultural católica, incrementada por bandas, festivais de música e livros, somada ainda à ascensão de comunidades de vida e de aliança como a Toca de Assis, Marcelo Camurça pergunta como essa efervescência pode estar relacionada com o descenso no número de católicos? Onde mais precisamente o catolicismo está diminuindo? São os carismáticos, os paroquianos, os integrantes das CEBs que abandonam as hostes católicas? (:74).

Silvia Fernandes conclama a urgente necessidade de pesquisas que busquem correlações entre as variáveis econômicas, sociais e culturais para explicar as diferenças regionais na distribuição dos católicos. Como, afinal, estaria o fenômeno migratório associado com o maior ou menor número de católicos? Seria essa uma chave analítica para compreender as regularidades no percentual de católicos entre as regiões com modalidades de migração semelhantes? (:113).

Regina Novaes, por sua vez, ao tratar dos jovens sem religião, sublinha que a ênfase comumente dada a "desfiliação" pode ocultar os significados da declaração sem 
religião entre os jovens. Modalidades de convivências de tempo e espaço dessa geração também redefinem e diversificam as formas de vínculo religioso. Assim, declarar-se "sem religião" não deve ser nem um ponto de partida e nem de chegada para as análises, mas deve, sobretudo, suscitar o interesse pelo mapeamento das lógicas e arranjos que resultam em diferentes maneiras de ser sem religião. $O$ desafio para as novas pesquisas é justamente o de conceber os jovens sem religião sem necessariamente desembocar na lógica do pertencimentos/não pertencimento institucional (:188).

Luciana Duccini e Miriam Rabelo convocam outros pesquisadores a refletir sobre a desigualdade de crescimento das religiões afro-brasileiras, sobretudo umbanda e candomblé, de modo que possam compreender, à luz de fatores sociais, mas também cosmológicos, os caminhos distintos que esses grupos parecem ter tomado (:228).

Elizabeth Pissolato, ao comparar os números do censo religioso entre os que se declararam indígenas, chama a atenção para a necessidade de novas pesquisas sobre o aumento exponencial daqueles que declaram "tradições indígenas" como sua religião, em face ao decréscimo no número de católicos, a estabilidade dos sem religião e o aumento moderado dos evangélicos (:242).

Ronaldo Almeida e Rogério Barbosa, no capítulo dedicado à transmissão religiosa, estimulam pesquisadores a elaborar trabalhos tendo como unidade de análise o domicílio. Tal feito permitiria diferenciar a capacidade de transmissão de cada religião e colocar em termos demográficos o lugar da família, e mesmo do domicilio, no macroprocesso de mudança religiosa (:312).

Religiões em movimento: o censo de 2010 não é somente uma obra que testemunha o panorama religioso brasileiro na primeira década do século XXI, mas trata-se de um livro que oferece, a um só tempo, reflexões sobre a presença das religiões no país em suas múltiplas faces e sobre os próprios termos a partir dos quais as ciências sociais da religião têm explorado o fenômeno religioso. Dedicado à memória de Clara Mafra e de Antônio Flávio Pierucci, Religiões em movimento reúne contribuições que, no espírito dos trabalhos destes cientistas sociais, longe de terminarem no censo, fazem dele um poderoso pretexto para encontrar novos horizontes de pesquisa e reflexão.

\section{Notas}

1 Com isso não sugiro que os números do censo religioso sejam um tópico de consenso, mas apenas indico seu lugar referencial para o desdobramento de discussões sobre temas variados. Aliás, a capacidade de constituir-se como um dispositivo universalizante e absoluto - por isso, referencial - é própria de mecanismos de produção de governo como os censos.

2 Embora os capítulos citados a seguir privilegiem a análise de determinadas categorias religiosas, isso não significa que eles não as extrapolem, mas, pelo contrário, trata-se na maior parte das vezes de "usar" a denominação como um ponto de partida privilegiado para reflexões mais amplas sobre religião e sobre o censo.

3 SANCHIS, Pierre. (2001), Fiéis $\mathcal{E}$ cidadãos: percursos de sincretismo no Brasil. Rio de Janeiro: Eduerj.

4 Ibidem, 2001:45. 
5 PIERUCCI, Antônio Flávio. (2006), "Modernidade religiosa à brasileira”. Clio (Lisboa), v. 14/15: 151172.

6 Idem 2006:57.

7 Idem 2006:58.

8 CAMARGO, Cândido Procópio Ferreira de. et al, (1973), Católicos, protestantes, espíritas. Rio de Janeiro: Vozes.

9 (Pierucci 2006: 46).

Rodrigo Toniol (rodrigo.toniol@gmail.com)

Doutorando em Antropologia Social pelo Programa de Pós-Graduação em Antropologia Social da Universidade Federal do Rio Grande do Sul - UFRGS. 